Department of Clinical Radiology, North Bristol NHS Trust, Bristol, UK

${ }^{2}$ Department of Radiology, Great Western Hospital, Swindon, UK

Correspondence to Dr Dhiraj Joshi, dhiraj. joshi62@gmail.com

Accepted 15 March 2014
CrossMark

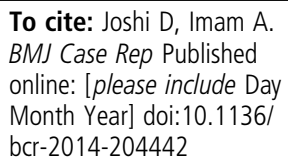

\title{
Volume rendered three-dimensional CT angiography for the diagnosis of arteriovenous fistula and pseudoaneurysm of the popliteal artery following knee arthroscopy
}

Dhiraj Joshi, ${ }^{1,2}$ Atique Imam $^{2}$

\section{DESCRIPTION}

A 24-year-old woman presented with a swollen right leg and a pulsatile lump in the popliteal fossa 3 days after a diagnostic knee arthroscopy. The CT arteriogram demonstrated a $6 \mathrm{~cm}$ pseudoaneurysm of the right popliteal artery (PA). There was early filling of the ipsilateral femoral vein with contrast medium, indicating an abnormal communication between the artery and the vein (figures 1 and 2). A volume rendered three-dimensional reconstruction of the axial images further helped to localise the exact site and size of the arteriovenous fistula $(\mathrm{AVF})$ as demonstrated in video 1 . The

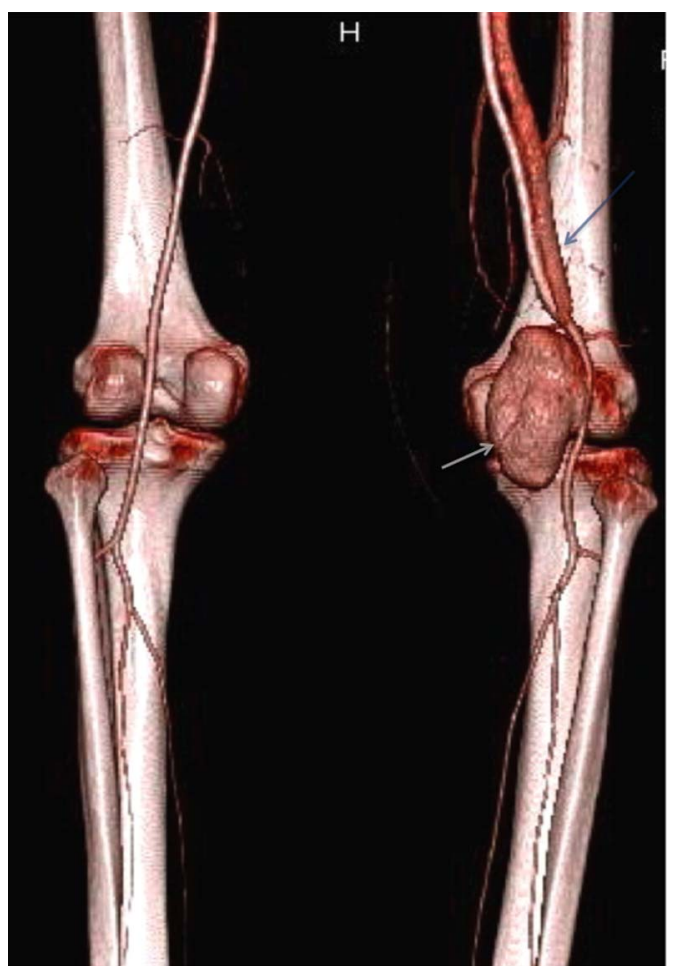

Figure 1 Volume rendered three-dimensional reconstruction of lower limb CT arteriogram. A pseudoaneurysm of the left popliteal artery and an arteriovenous fistula with the common femoral vein is shown. The grey arrow indicates the pseudoaneurysm and the blue arrow shows the early filling of the common femoral vein. Note the femoral vein on the contralateral side is not opacified.

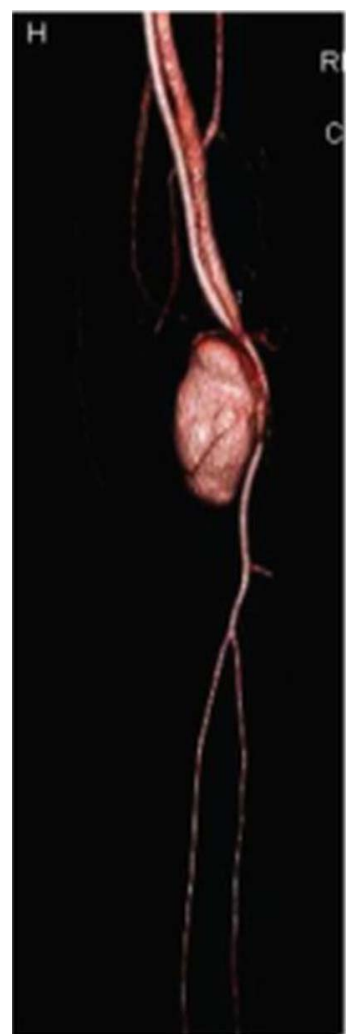

Figure 2 Volume rendered three-dimensional reconstruction of lower limb CT arteriogram. The bone removal software has been used to further delineate the anatomy of the popliteal artery pseudoaneurysm and arteriovenous fistula.

pseudoaneurysm would have been amenable to percutaneous thrombin injection, but this was contraindicated in the presence of an $\mathrm{AVF}^{1}$ as thrombin leakage into the deep veins would cause thrombosis and a potential pulmonary embolism. Another alternative was to deploy a covered stent-graft within the PA, but there were concerns regarding its long-term patency around the joint. ${ }^{2}$ An open surgical repair was eventually performed. The PA was ligated proximal and distal to the AVF and the autologous reversed saphenous vein was used to bypass the ligated PA. There was resolution of venous hypertension and preservation of distal arterial perfusion. 


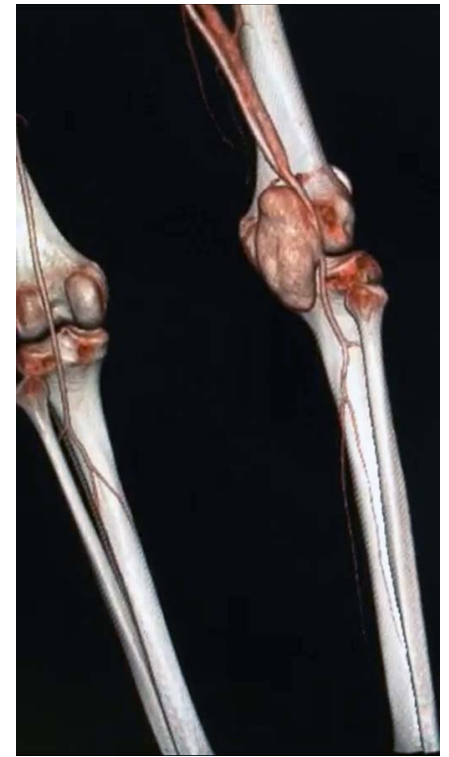

Video 1 A 360-degree view of the volume rendered threedimensional reconstruction of lower limb CT arteriogram. A pseudoaneurysm of the left popliteal artery and an arteriovenous fistula with the common femoral vein is demonstrated.

\section{Learning points}

- Although rare, serious vascular injury is possible during knee arthroscopy.

- Early filling of veins during an arterial phase CT scan could be due to an arteriovenous fistula, so comparison with the contralateral side is advised.

- Volume rendered three-dimensional reconstruction defines the anatomy accurately and helps the multi-disciplinary team decide on optimum management.

Contributors DJ: prepared the case report; Al: edited the case report.

Competing interests None.

Patient consent Obtained.

Provenance and peer review Not commissioned; externally peer reviewed.

\section{REFERENCES}

1 Hanson JM, Atri M, Power N. Ultrasound-guided thrombin injection of iatrogenic groin pseudoaneurysm: Doppler features and technical tips. Br J Radiol 2008;81:154-63.

2 Tielliu IF, Zeebregts CJ, Vourliotakis G, et al. Stent fractures in the Hemobahn/ Viabahn stent graft after endovascular popliteal aneurysm repair. J Vasc Surg 2010;51:1413-18.

Copyright 2014 BMJ Publishing Group. All rights reserved. For permission to reuse any of this content visit http://group.bmj.com/group/rights-licensing/permissions.

BMJ Case Report Fellows may re-use this article for personal use and teaching without any further permission.

Become a Fellow of BMJ Case Reports today and you can:

- Submit as many cases as you like

- Enjoy fast sympathetic peer review and rapid publication of accepted articles

- Access all the published articles

- Re-use any of the published material for personal use and teaching without further permission

For information on Institutional Fellowships contact consortiasales@bmjgroup.com

Visit casereports.bmj.com for more articles like this and to become a Fellow 